\title{
Scripts para o palco das entrevistas de emprego
}

\author{
Cesar Martins Guimarães ${ }^{1}$
}

Instituto de Psicologia da Universidade de São Paulo

\begin{abstract}
O objetivo deste estudo é explorar a institucionalização do trabalho no século XXI e seu impacto sobre o objeto da Psicologia Organizacional a partir da análise do conteúdo de publicações brasileiras na internet que se propõem a dar conselhos àqueles que se submeterão a uma entrevista de emprego. Foram estabelecidas quatro categorias distintas de conselhos, segundo o conteúdo que expressam: afetiva, emocional, estética e ética. Foram identificados três afetos como os mais recorrentemente citados: a lealdade, o interesse e o respeito. No que tange às emoções, os conselhos estabelecem emoções negativas que devem ser ocultadas (insegurança e ódio) e emoções positivas a serem manifestadas (principalmente o entusiasmo). Os scripts estéticos abordam a vestimenta, a fala e os estigmas corporais. São elitistas e postulam, de forma reificante, os trabalhadores como mercadorias contidas em embalagens. Os scripts éticos, por seu turno, são confusos e prescrevem a ética do cinismo racional. De forma geral, a análise dos scripts para as entrevistas de emprego evidencia que o tipo de relação prescrito para os trabalhadores com o mercado de trabalho é o adaptativo aos afetos, às emoções, à estética e à ética demandada: pressões ingênuas da ideologia da adaptação constituem o material de que são feitos esses scripts, tentativas de pré-formar subjetividades não reflexivas, poder exercido pela sociedade instituída.
\end{abstract}

Palavras-chave: Entrevistas de emprego, Afetos no trabalho, Emoções no trabalho, Estética no trabalho, Ética no trabalho.

\section{Scripts for the stage of job interviews}

The aim of this study is to explore the institutionalization of work in the twenty-first century and its impacts on the object of Organizational Psychology analyzing the content of Brazilian publications on the Internet that purport to give advice to those who will undergo a job interview. It was established four separate categories of advices, according to the expressed content: affective, emotional, aesthetic and ethical. It was identified three affections as the most widely cited: the loyalty, the interest and the respect. With regard to emotions, the advice is that negative emotions should be hidden (insecurity and anger) and positive emotions expressed (mainly the enthusiasm). The aesthetic scripts deal with the dressing, speech and body stigmas. They are elitist and postulate, reifying, workers as commodities contained in packages. Ethical scripts, in turn, are confusing and prescribe the ethics of rational cynicism. In general, the analysis of the scripts for job interviews shows that the kind of relationship prescribed for workers on the job market is adaptive to the affects, emotions, aesthetics and ethics demanded: naive pressures from the ideology of adaptation are the material they are made from, attempts to pre-form non-reflective subjectivity, power exercised by the instituted society.

Keywords: Job interviews, Affections at work, Emotions at work, Aesthetics at work, Ethics at work.

Porque eu posso sorrir e matar enquanto sorrio,

E gritar "Ótimo!" para o que aflige meu coração,

E umedecer minhas faces com lágrimas artificiais,

E moldar meu rosto para todas as ocasiões.

Eu afogarei mais marinheiros do que poderia a sereia,

Eu exterminarei mais contempladores do que o basilisco;

Eu discursarei tão bem quanto Nestor,

Enganarei mais maliciosamente do que poderia Ulisses,

E, como Sinon, conquistarei outra Troia.

Posso acrescentar cores ao camaleão,

Alterar convenientemente as formas, como Proteu,

E mandar o sanguinário Maquiavel para a escola.

Posso fazer tudo isso e não posso ter uma coroa?

Ora, não importa como, eu a conseguirei. ${ }^{2}$

1 Doutorando em Psicologia Social do Trabalho.

2 Fala de Richard, que se tornaria rei Ricardo III, na peça teatral Rei Henrique VI, parte 3, de William Shakespeare (em tradução livre do autor). 


\section{Introdução}

$\mathrm{O}$ objetivo deste estudo é explorar a institucionalização do trabalho no século XXI e seu impacto sobre o objeto da Psicologia Organizacional (PO) a partir da análise do conteúdo de publicações brasileiras na internet que se propõem a dar conselhos àqueles que se submeterão a uma entrevista de emprego.

Essas publicações, que se apresentam em grande número, não só para o público brasileiro, contêm recomendações gerais de como se portar ao ser entrevistado, o que deve ser transmitido e que sinais devem ser intencional e conscientemente emitidos pelo entrevistado. Como mostra Norbert Elias em O processo civilizador, um estudo publicado em 1939 sobre os tipos de comportamento considerados típicos do homem civilizado ocidental desde o período medievo-feudal, vários livros surgiram no decorrer da História para ensinar pessoas a se comportar em diversas situações, sugerir padrões estéticos que deveriam ser observados, além de afetos, emoções e vontades que deveriam ser sentidos e manifestados. Esse é o caso dos conteúdos publicados na internet sobre entrevistas de emprego.

Além de "civilizar" seus leitores, expressando normas "apropriadas", esses conteúdos revelam uma relação de poder e uma autoimagem elitizada dos gestores de pessoas que assinam a autoria dos textos. Dessa forma, tanto o processo civilizador, que se expressa em padrões pessoais demandados pelo mercado de trabalho contemporâneo, como a relação de poder presente nas entrevistas de emprego e a autoimagem dos gestores de pessoas serão explorados a partir de uma análise desses conteúdos.

A escolha desses scripts como o objeto da pesquisa justifica-se por serem as situações de entrevista de emprego uma das quais as demandas do mercado de trabalho explicitam em sua plenitude.

\section{Subjetividade e a institucionalização do trabalho no século XXI}

A subjetividade do trabalhador, que nos primórdios do capitalismo se interpunha como uma barreira à padronização do trabalho, apresenta-se no capitalismo reestruturado como um fator de qualidade, produtividade e, portanto, de competitividade das empresas. Esse fato faz com que a empresa capitalista hoje precise subsumir por completo, material e subjetivamente, de corpo e alma, o trabalhador ao capital. A resposta gerencial a essa necessidade institui-se, a princípio, na forma de modelos de gestão do conhecimento (subjetividade cognitiva) para em seguida ganhar a forma de modelos de gestão de competências (subjetividade ampliada, não apenas cognitiva, mas também volitiva e afetiva). Exige-se do trabalhador uma predisposição permanente ao trabalho e ao automelhoramento profissional na forma de ampliação de conhecimentos e autocontrole das emoções e desejos funcionais à produção e entrega de mercadorias. Com isso, processos de seleção, retenção, avaliação, desenvolvimento, controle e remuneração dos trabalhadores ganham novos formatos na empresa contemporânea.

Gorz sustenta que o conhecimento se constituiu como a principal força produtiva do capitalismo contemporâneo e que, em decorrência, "os produtos da atividade social não são mais, principalmente, produto do trabalho cristalizado, mas sim do conhecimento cristalizado" (Gorz, 2005, p. 29), uma vez que no capitalismo reestruturado o valor de troca das mercadorias não é mais determinado, em última análise, pela quantidade de trabalho socialmente necessário para produzi-las, mas pelo seu conteúdo de conhecimento e inteligência, impossível de ser 
traduzido e mensurado em unidades abstratas simples, irredutíveis a uma quantidade de trabalho abstrato.

$\mathrm{Na}$ verdade, conhecimento comporta apenas parte das competências humanas com possibilidade de serem melhoradas em sua potencialidade produtiva. Portanto, talvez fosse mais preciso dizer que os produtos da atividade social no capitalismo reestruturado são principalmente resultado da subjetividade - conhecimentos, vontades e afetos - cristalizada, algo que já chamava a atenção de Wright Mills em meados do século XX:

Quando arranjam um emprego, os colarinhos-brancos não vendem apenas o seu tempo e energia, mas também suas personalidades. Vendem por semana ou por mês o sorriso e os gestos amáveis, e devem exercitar a pronta repressão do ressentimento e da agressividade. Esses traços pessoais têm relevância comercial, são necessários à distribuição mais rendosa dos bens e serviços. E eis-nos diante dos novos pequenos maquiavéis, alugando seus talentos pessoais para lucro de outros, segundo regras estipuladas pelos seus superiores (Wright Mills, 1951/1979, p. 19).

A esse respeito, Gorz vislumbra que:

o desempenho repousa sobre sua implicação subjetiva, chamada também "motivação" no jargão administrativo, gerencial. $\mathrm{O}$ modo de realizar as tarefas, não podendo ser formalizado, não pode tampouco ser prescrito. O que é prescrito é a subjetividade, ou seja, precisamente isso que somente o operador pode produzir ao "se dar" à sua tarefa. As qualidades impossíveis de demandar, e que deles são esperadas, são o discernimento, a capacidade de enfrentar o imprevisto, de identificar e de resolver os problemas (Gorz, 2005, p. 18).

Obviamente, uma metamorfose de tal intensidade no mundo do trabalho alterou significativamente, e na direção de uma crescente complexidade, as demandas sobre a Psicologia Organizacional como atividade prático-poiética, isto é, que se constrói a partir de sua praxis. Como nota Malvezzi: "é improvável que a PO, como conhecimento especializado sobre o desempenho humano nas organizações, transite incolumemente da empresa estável, articulada pela tecnologia eletromecânica e o sistema gerencial, para a empresa globalizada, articulada pela teleinformação e o empreendedorismo" (Malvezzi, 1999, p. 314). Nascida para a compreensão da - e a intervenção na - relação trabalhador-máquina circunscrita pela tarefa, a PO lançou inicialmente foco sobre a fadiga - ao mesmo tempo resultado e obstáculo à eficiência produtiva dessa relação - e a divisão de tarefas, como forma de ajustamento do trabalhador à máquina com vistas a tornar essa relação mais produtiva. A busca da produtividade apoiava-se na crença de que a relação homem-máquina deveria ser calculável, previsível e padronizável. A perspectiva da "engenheirização" da relação homem-máquina, que encerra a visão do homem como apêndice da máquina, abre um amplo campo à aplicação de técnicas psicométricas a serviço do controle gerencial.

A partir do final da Segunda Grande Guerra, quando as mudanças no mundo do trabalho começam a se pronunciar e a chamar a atenção de pensadores em diversas áreas do conhecimento, trazendo à tona o fato de que o desempenho humano no trabalho não pode ser abstraído da regulação social, econômica, política e cultural, a relação trabalhador-máquina cede espaço para a investigação da relação trabalhador-organização. Como consequência, outros temas começam a ocupar as agendas de pesquisa da $\mathrm{PO}$, como a comunicação e a liderança. Trata-se de um movimento que, se a princípio mostra-se tímido, vai ganhando força até se estabelecer como corpo na Teoria dos Sistemas Sociotécnicos e na Teoria do Desenvolvimento Organizacional. 
O advento dos anos 1980 consolida a virada subjetivista da PO: a perspectiva da engenharia homem-máquina perde relevância nas agendas de pesquisa para temas mais ligados à cognição, afetos e vontades no trabalho, o que ocorre sob influência da crescente internacionalização das empresas, a precarização das relações de trabalho e o consequente fim das carreiras de longo prazo, além da instabilidade na demanda por trabalhadores, não só numérica, mas também no que diz respeito a quais seriam as competências demandadas, dadas as instabilidades e ambiguidades dos desígnios do mercado global. Os estudos dos processos de aprendizagem ganham destaque nas agendas de pesquisa: a capacidade de adaptar-se rapidamente - ao que em pouco tempo já não será - vira condição de empregabilidade, e a PO lança suas lentes para a relação trabalhador-mercado. A organização não se mostra mais como um suporte apto a sustentar uma trajetória profissional contínua e ascendente, e o trabalhador deve aprender, de alguma forma, a nadar acima das ondas do revolto mercado de trabalho. É nesse contexto que o tema do trabalhador empreendedor, do contrato psicológico e do compromisso - ambos temporários - e da identidade profissional e sua labilidade passam a habitar mais frequentemente os estudos da PO.

Impõe-se, portanto, como tarefa à $\mathrm{PO}$ elucidar essa relação do humano com o mercado, significação imaginária social-histórica, ser transcendentalizado e que parece pairar ameaçador sobre a cabeça dos trabalhadores como um deus posto no lugar do Deus morto, agindo segundo desígnios próprios e desintegrando a memória de que ele mesmo é criação humana. Que tributos e sacrifícios esse deus cobra de seus súditos e que promessas oferece em troca? São vários os evangelhos, muitos os profetas: um amplo material que se coloca à disposição da pesquisa no campo da PO. Das muitas vias por onde a palavra desse novo deus ex machina se manifesta, este estudo se detém nos scripts para o palco das entrevistas de emprego.

\title{
A cena e os scripts: comportamento e subjetividade prescritos
}

\begin{abstract}
Quando um indivíduo surge na presença de outro, este habitualmente procura obter informações sobre ele ou recorrer a informações que já possuam a seu respeito. Interessarse-á pelo estatuto socioeconômico global, pelo que o indivíduo pensa de si próprio, pela sua atitude para com eles, pela sua competência, pelo grau de confiança que ele merece etc. Embora parte dessa informação pareça ser procurada por si mesma, geralmente existem razões bastante práticas justificando a sua aquisição. As informações sobre o indivíduo ajudam a definir a situação, permitindo aos outros saber de antemão o que espera o indivíduo deles e o que poderão eles esperar do indivíduo. Se dispuserem das informações adequadas, os outros saberão melhor como devem atuar, a fim de obterem do indivíduo a resposta que desejam (Goffman, 1959/1993, p. 11).
\end{abstract}

Essas palavras, escolhidas pelo sociólogo canadense Erving Goffman para abrir a introdução de seu livro A apresentação do eu na vida de todos os dias, referem-se a encontros entre pessoas em suas vidas cotidianas e podem ser utilizadas para descrever um tipo de encontro particular: as entrevistas de emprego. Durante a entrevista, o entrevistador busca, a partir do comportamento e aparência do entrevistado, pistas que lhe permitam utilizar teorias nas quais acredita e experiências que já possui para formular uma avaliação. Apesar da aura de um processo totalmente científico de investigação da realidade, esse procedimento geralmente não consegue ir muito além da aplicação de estereótipos não verificados, considerando que o tempo dessa interação será insuficiente para que se reúnam informações conclusivas, como nos ensina Goffman: 


\begin{abstract}
Numerosos são os fatos decisivos que se encontram para lá do tempo e lugar da interação ou que se escondem no interior do seu quadro. Por exemplo, as "verdadeiras" ou "reais" atitudes, crenças e emoções do indivíduo só indiretamente poderão ser apreciadas, através das suas confidências ou daquilo que se manifesta como um comportamento involuntariamente significativo. [...] Serão forçados a aceitar alguns acontecimentos como signos naturais ou convencionais de alguma coisa que não é imediatamente acessível aos sentidos (Goffman, 1959/1993, p. 12).
\end{abstract}

A partir dessas pistas, a tarefa do entrevistador é criar os meios que tornem possível, ou criem a ilusão de que seja possível, a previsão do desempenho futuro do entrevistado caso ele venha a ser contratado. Obviamente, a avaliação pressupõe o cotejo do desempenho previsto com padrões de desempenho desejáveis. São exatamente esses padrões desejáveis que esse estudo busca capturar nos scripts publicados. Há que se ressaltar que a entrevista de emprego é apenas uma das técnicas comumente utilizadas na seleção de pessoal. Apesar de considerarem a entrevista como o instrumento mais importante de seleção, Limongi-França e Arellano (2002) relacionam outras técnicas que podem e são utilizadas frequentemente: as provas de conhecimento, os testes psicológicos, as técnicas vivenciais e a avaliação de saúde. A aplicação de cada uma dessas técnicas busca, da mesma forma que a entrevista de emprego, a previsibilidade do desempenho. A esse respeito Limongi-França e Arellano sustentam que "todos os métodos psicométricos preveem uma margem de acerto e erro, por isso não são a expressão do futuro, mas a predição” (Limongi-França \& Arellano, 2002, p. 67).

Observando o ponto de vista do entrevistado, certamente este tentará direcionar o entrevistador para uma avaliação positiva, seja transmitindo verbalmente coisas que supostamente o entrevistador espera ouvir de alguém que tenha sido definido como adequado para ocupar a posição, seja emitindo sinais que ele supõe sejam sintomáticos de alguma competência também supostamente definida como importante para o ocupante dessa vaga. Essa distinção entre a expressão (verbal) que transmite e a expressão (verbal ou não verbal) que emite tem, segundo Goffman, apenas uma validade inicial: "O indivíduo transmite, sem dúvida, falsas informações de modo intencional através dos dois tipos de comunicação, correspondendo o primeiro à fraude, o segundo à dissimulação" (Goffman, 1959/1993, p. 12).

Seja recorrendo à fraude, à dissimulação, seja tentando expressar a "verdade", o papel do entrevistado nunca é passivo na interação. Será de seu interesse controlar o comportamento do entrevistador, principalmente a avaliação que este fará. Nas palavras de Goffman, "quando um indivíduo se apresenta diante de outros, haverá geralmente motivos que o levem a mobilizar seus atos de modo a veicular para os outros a impressão que ao indivíduo interessa veicular" (Goffman, 1959/1993, p. 14). A resposta à pergunta "que impressões interessa veicular?" pode ser encontrada parcialmente nos conteúdos sobre entrevistas de emprego publicados na internet. Parcialmente porque esses conteúdos expressam prescrições gerais, apesar de a subjetividade prescrita não ser independente da categoria de trabalho que se está considerando nem das instituições sociais presentes. Essa questão merece um tópico em separado.

\title{
Subjetividade prescrita e as categorias de trabalho
}

Reich (1994) identifica três amplas categorias de trabalho no setor de serviços que denomina respectivamente de serviços rotineiros de produção, serviços pessoais e serviços simbólico-analíticos. Os trabalhos da primeira categoria "guardam estreito vínculo com as classes de tarefas repetitivas que eram executadas pelos antigos peões do capitalismo americano na empresa de larga escala" (Reich, 1994, p. 162). Nessa categoria, a subjetividade individual 
pode ser vista pela gestão como uma dificuldade à necessidade de padronização das tarefas. Muitos trabalhos se enquadram nessa categoria, mesmo no segmento da alta tecnologia, como é o caso dos processadores de dados que, de forma rotineira e padronizada, introduzem, processam e recuperam dados de computadores. O valor que essas tarefas geram está intimamente relacionado com o tempo de trabalho.

Os serviços pessoais, a segunda categoria proposta por Reich, têm como principal diferença em relação à categoria anterior o fato de serem executados pessoa a pessoa, ou por pequenas equipes, não podendo, portanto, ser comercializados em caráter mundial. Segundo Reich, "dos servidores pessoais espera-se que sejam pontuais, confiáveis e de fácil trato, como os trabalhadores rotineiros da produção. Todavia, muitos dos servidores pessoais devem ainda apresentar uma outra qualidade: comportar-se de forma simpática e agradável" (Reich, 1994, p. 164). Nessa categoria enquadram-se os vendedores de varejo, garçons, atendentes, caixas, secretários, cabeleireiros, corretores de imóveis, mecânicos de automóveis, comissários de bordo, fisioterapeutas e guardas de segurança. Esses trabalhadores entram no processo de produção e distribuição de mercadorias não somente com seu conhecimento, mas também manifestando e omitindo afetos e desejos na relação cliente-fornecedor.

A terceira categoria descrita, a dos serviços simbólico-analíticos, engloba as atividades em que "o que se comercializa são manipulações de símbolos - dados, palavras, representações orais e visuais" (Reich, 1994, p. 163). Em seu trabalho concreto, os analistas simbólicos identificam e conceituam problemas, desenvolvem soluções e planejam sua execução, manipulando símbolos com o uso de ferramentas analíticas. Essas ferramentas podem ser tanto algoritmos matemáticos quanto argumentos, princípios científicos, conhecimentos psicológicos ou artifícios financeiros. Esses analistas "simplificam a realidade por meio de imagens abstratas que podem ser re-arranjadas, embaralhadas, experimentadas e comunicadas a outros especialistas, e então, eventualmente transformadas de volta em realidade" (Reich, 1994, p. 165). Nessa categoria enquadram-se os consultores, executivos, diretores artísticos, pesquisadores, psicólogos e advogados, profissões nas quais conhecimentos específicos são funcionalmente valorizados e expressões de emoções consideradas socialmente negativas são mais toleradas, vistas pelo imaginário social como "excentricidades naturais".

Apesar de essa diferenciação da subjetividade prescrita para cada categoria de trabalho ser evidente, o conteúdo publicado sobre as entrevistas de emprego na internet não apresenta um nível de profundidade tal que a capture. Outras diferenciações de subjetividade prescrita que são recorrentemente identificadas em trabalhos no campo que trata das emoções sob a ótica social, como as distinções de raça, idade, etnia e poder, também passam ao largo desses conteúdos. Adicionalmente, há razões práticas para se suspeitar que a subjetividade demandada não é independente do tipo de negócio em questão ou mesmo do que se convencionou chamar de cultura organizacional: os scripts para alguém que vá concorrer a uma vaga de recepcionista em uma loja de antiguidades, por exemplo, podem não servir para os que vão concorrer a uma vaga de recepcionista em uma loja de tatuagens. Apesar disso, a única diferenciação presente nos conteúdos analisados diz respeito a conselhos específicos sobre a vestimenta para mulheres. Os conteúdos analisados tratam mais de conselhos gerais, mas que, de alguma forma, expressam a fala daqueles que demandam trabalho e têm poder de escolha. Apesar dessa limitação, a análise desses conteúdos ainda pode ser capaz de ajudar na elucidação parcial da subjetividade demandada pelo mercado no século XXI. 


\section{A pesquisa dos scripts}

A amostra coletada constitui-se de trinta diferentes sítios, publicados em língua portuguesa e hospedados no Brasil, cujo conteúdo expressa conselhos àqueles que irão se submeter a uma entrevista de emprego. A pesquisa se deteve a esse número de sítios por julgamento do pesquisador, após a constatação de que havia um padrão que se mantinha: novos sítios não apresentavam novidades em relação aos já consultados. A seleção foi feita a partir do uso do mecanismo de procura na internet Google, que retornou mais de oitocentas mil conexões para a expressão "entrevista de emprego". Ao fim, a amostra foi composta pelos trinta primeiros sítios na ordem apresentada pelo mecanismo de busca que cumpriam os requisitos estabelecidos, isto é, que continham conselhos destinados aos entrevistados, escritos em língua portuguesa e hospedados no Brasil.

A amostra foi submetida a dois procedimentos de análise distintos. Inicialmente, uma análise qualitativa permitiu o estabelecimento de categorias gerais de conselhos. A seguir, uma análise quantitativa apurou a frequência dos conselhos.

A análise qualitativa permitiu agrupar os conselhos em quatro categorias distintas de acordo com o conteúdo que expressam: dimensão afetiva, dimensão emocional, dimensão estética e dimensão ética. Para tornar mais clara essa classificação, faz-se necessário que se explicite o entendimento sobre cada um desses quatro construtos que nomeiam as categorias que surgiram na pesquisa.

\section{Dimensão afetiva}

Entenda-se afeto como um resultante do processo de sublimação. Usando a metáfora econômico-energética freudiana, o afeto é constituído de um quantum (intensidade) e de um sinal (positivo, de prazer, ou negativo, de desprazer) com os quais um objeto é investido, uma quantidade que se vivencia como qualidade. Assim, é inegável haver uma relação entre afeto e representação, mas há também uma relativa independência e uma impossibilidade de, a priori, se estabelecer uma relação de causalidade unívoca entre essas duas dimensões do investimento sublimado. Como ensina Castoriadis:

Há certamente alguns casos em que predomina uma nota afetiva negativa e nos quais tudo o que acontece ao sujeito é interpretado a partir dessa nota afetiva negativa; e outros casos, que teríamos a tendência de considerar mais "normais", onde há uma espécie de primazia do trabalho representativo, onde o sujeito constrói constantemente o mundo como hostil ou simplesmente deprimente, o que suscita o afeto depressivo (Castoriadis, 2007, pp. 105-106).

O fato de o afeto poder operar de uma forma relativamente independente da representação decorre, portanto, da possibilidade de desfuncionalização e autonomização do desejo no psiquismo humano, ao contrário do que acontece com o psiquismo animal. O prazer decorrente de certo estado de sublimação se sobrepõe àquele obtido no nível do órgão, a preservação do significado de si supera inclusive o valor da preservação do ser biológico.

Assim, a categoria afetiva que resultou da pesquisa engloba conselhos sobre que afetos devem ser expressos durante a entrevista e as formas de manifestá-los. 


\title{
Dimensão emocional
}

Entenda-se o conceito de emoção como fundamentalmente psicossocial-histórico, pois decorrem da complexidade do construto emoções que a própria definição do que seja emoção apresente diversas versões, algumas conflitantes. A ortodoxia funcionalista, em suas diversas nuances, tende a encarar a emoção simplesmente como uma resposta funcional a um estímulo. Apesar de essa explicação ser plausível quando estamos nos referindo a emoções em animais, como, por exemplo, o medo como emoção funcional à sobrevivência por incitar a ação de fuga do predador, não se pode esquecer que, no decorrer da história da socialização, as emoções foram desfuncionalizadas, isso é, carregadas de componentes simbólicos. Castoriadis (2007) argumenta que a desfuncionalização do aparelho psíquico, e consequentemente das emoções, é característica da história da socialização:

\begin{abstract}
A predominância da imaginação condiciona a não funcionalidade do aparelho psíquico humano. Para o animal, pode-se dizer que aquilo que existe como embrião do aparelho psíquico tem uma função: conservação do indivíduo e da espécie. [...] No humano, essa lógica é quebrada, utilizada por ele de modo quase sempre contraditório, pois, como dizia Freud, não somente o inconsciente ignora a contradição - em um sonho constatam-se quase sempre desejos contraditórios, mais ou menos realizados simultaneamente -, mas também, o que Freud não percebia, na vida diurna e acordada todo mundo tem constantemente desejos incompatíveis e contraditórios, ou seja, vive constantemente segundo o princípio de que "tua mão esquerda ignora o que faz a direita" (Castoriadis, 2007, p. 29).
\end{abstract}

Salvatore e Venuleo (2008), em sua crítica às teorias funcionalistas da emoção, sustentam que:

Em primeiro lugar, os sujeitos não entram em contato com um objeto simples, discreto. Obviamente, cada um de nós experimenta uma manifestação discreta do mundo, percebido com conteúdos específicos; mas este é o resultado da atribuição de sentidos, não do estímulo. Objetos são produtos de um trabalho recursivo e sistemático de diferenciação, separação e de emprestar relevâncias ao intrinsecamente contínuo campo de experiências. Desse ponto de vista, o sujeito não encontra o objeto, mas está imerso em uma densa rede de um infinito número de potenciais conexões no interior do fluxo ambiental de energiamatéria disposta ao longo da linha do tempo. Isso significa que, para um objeto ser representado, precisa, primeiramente, ser extraído do fluxo. [...] Duas pessoas engajadas com o mesmo campo de experiências, mas tendo posições diferentes, serão capazes de construir diferentes objetos (Salvatore \& Venuleo, 2008, p. 34).

Portanto, nessas visões a percepção de um evento não acontece antes de se atribuir um significado a ele. Decorre dessa tese que toda experiência emocional é interpretativamente mediada. Ao interpretar seu campo existencial - e sua própria experiência emocional como parte desse campo existencial - os sujeitos constroem e reconstroem continuamente suas emoções e não se submetem passivamente a elas. Entretanto, há que se ressaltar que as ações e defesas dos sujeitos sobre sua própria experiência emocional não podem ser totalmente garantidas: emoções não são totalmente previsíveis, consistentes e gerenciáveis, podendo, inclusive, ser caóticas, a despeito das tentativas de controlá-las, domesticá-las e isolá-las. Além disso, ao se atribuir significado a qualquer objeto faz-se referência a um magma de significações imaginárias instituídas social e historicamente que regulam nossas atribuições de significados individuais e são reciprocamente por elas construídas. Da mesma forma, estruturas sociais - de poder, desigualdades, classe e status - servem de reguladores às experiências emocionais.

Outra característica relevante da emoção, nos termos como caracterizada neste estudo, é que, além de sempre se referir a um objeto (coisa, pessoa, animal, evento, fantasia, memória, 
outra emoção etc.) tornado discreto do campo existencial contínuo pela atividade de interpretação, é também necessariamente circunscrita no tempo. Essa característica a diferencia dos sentimentos: enquanto uma experiência emocional tem necessariamente uma duração temporal, um sentimento pode persistir por toda uma vida.

Assim, a categoria emocional que resultou da pesquisa diz respeito à capacidade de gerenciar as próprias emoções, classificando as emoções em positivas, e, portanto, a serem expressas, e negativas, cuja expressão deve ser controlada.

\section{Dimensão estética}

Entenda-se estética no seu sentido mais corriqueiro, isto é, a percepção e o julgamento do que é considerado belo. O importante aqui é ressaltar que essa percepção é social e historicamente regulada e que o julgamento pressupõe uma reflexividade crítica, entendida como uma faculdade de separar, de distinguir. Dessa forma, o belo não é aqui postulado com um sentido metafísico, um fator da ordem universal, mas uma praxis socialmente significada no sentido castoriadiano do termo - e, portanto, um sentido que expressa a afirmação do belo como uma superioridade socialmente instituída.

Assim, a categoria estética que resultou da pesquisa promove padrões de julgamento estético a serem perseguidos por serem julgados superiores.

\section{Dimensão ética}

Entenda-se ética - o conteúdo de uma máxima a direcionar toda ação na qual seres humanos estejam implicados - como uma praxis voltada ao projeto de autonomia e da vida boa. A ética, portanto, está intimamente ligada ao conceito de bem. Entretanto, em concordância com o pensamento castoriadiano, há que se postular que nenhuma ética tem a capacidade de responder a todas as questões do tipo "o que devo fazer?" que poderão aparecer no decorrer da vida de um homem e, portanto, não há alternativa que não seja reconhecer essa trágica condição humana: não há regra abstrata ou mandamento universal que possa nos livrar da responsabilidade de nosso agir - necessariamente situado no particular e não no universal, e que, portanto, não prescinde de reflexão e julgamento. Desse postulado decorre o fato de se entender a ética como praxis. Assim, o sujeito ético não experimenta somente conflitos internos: o próprio conteúdo do que seja considerado o bem deve ser instituído e nunca será uma disposição pura, natural, metafísica ou divina, mas social-histórica: "temos que criar o bem em condições imperfeitamente conhecidas e incertas; o próprio projeto de autonomia é, para nós, fim e guia, mas não resolve para nós as situações efetivas" (Castoriadis, 1999, p. 63). Adicionalmente, uma vez que os atos éticos são necessariamente atos que visam à autonomia, a ética, assim como a estética, não pode ser destacada abstratamente da política.

Assim, a categoria ética que resultou da pesquisa revela a ética prescrita aos trabalhadores - o que deve ser considerado o bem -, por ser demandada pelo mercado de trabalho.

\section{Análise dos scripts}

Ao se confrontarem as categorias que surgiram na pesquisa qualitativa com as teorias dominantes sobre competências, dois fatos saltam aos olhos: o primeiro é o surgimento de uma 
competência estética que as teorias praticamente ignoram; o segundo, o não surgimento de uma categoria relacionada ao conhecimento, cuja importância as teorias ressaltam. A explicação ao primeiro fato pode estar na preocupação da teoria em não revelar ou estabelecer estereótipos preconceituosos baseados em padrões estéticos elitistas que na prática são utilizados por aqueles que têm o poder de selecionar trabalhadores. A explicação ao segundo fato pode ser o reconhecimento de que a entrevista de emprego não é uma forma adequada à avaliação de conhecimentos, sendo preciso, para tal, recorrer a outras técnicas, como as provas de conhecimento e as análises de currículo. A análise do conteúdo extraído da amostra percorrerá cada uma dessas categorias em tópicos separados.

\section{Scripts afetivos}

A totalidade dos sítios pesquisados apresenta scripts afetivos, na forma de recomendações sobre que afetos devem transparecer nas entrevistas de emprego. Foram identificados três afetos como os que mais recorrentemente citados: a lealdade (presente em $80 \%$ dos sítios pesquisados), o interesse (presente em $77 \%$ dos sítios pesquisados) e o respeito (presente em $57 \%$ dos sítios pesquisados).

\section{A lealdade prescrita}

São considerados sinais de lealdade não falar mal de antigos empregadores (citado em $92 \%$ dos sítios que prescrevem a lealdade), ser pontual (50\% dos sítios que prescrevem a lealdade), não tomar a iniciativa de abordar durante a entrevista questões relativas a remuneração e benefícios ( $33 \%$ dos sítios que prescrevem a lealdade) e deixar clara a predisposição de colocar os interesses da organização acima dos interesses pessoais no que diz respeito a aspectos outros que não a remuneração e os benefícios ( $21 \%$ dos sítios que prescrevem a lealdade).

Algumas frases extraídas dos conteúdos que compuseram a amostra estudada podem servir para ilustrar a abordagem dada aos sinais de lealdade referidos. É paradigmático do conselho não falar mal de antigos empregadores a recomendação "Fale-me de problemas que você já teve com chefes anteriores. Não caia nesta. O entrevistador está te testando para saber se você falará mal dos seus chefes antigos. Simplesmente responda esta pergunta com tato, diplomacia e, se necessário, uma grande amnésia. Recentemente, você não teve problema algum".

A preocupação pela pontualidade pode ser ilustrada pela recomendação "Seja pontual. Evite ser 'português' nesse aspecto, basta chegar cerca de 15 minutos antes do horário acordado para a entrevista". Para além da ideia estereotipada que relaciona a nacionalidade portuguesa à falta de inteligência, a frase associa o fato de não se esforçar para sinalizar lealdade a uma burrice. Outra frase ilustrativa do aspecto pontualidade, por expressar claramente o poder na relação entrevistado-entrevistador, é "vá preparado para esperar. Você não pode atrasar, mas a pessoa que vai te entrevistar pode".

Uma frase representativa entre aquelas que sugerem não ser de bom tom tomar a iniciativa de levantar questões salariais durante a entrevista poderia ser: "o que te motiva a fazer um bom trabalho? A resposta a esta pergunta nunca é dinheiro, mesmo que, na realidade, seja. Você deve estar motivado por objetivos de vida nobres. Você quer reconhecimento por um trabalho bem feito. Você quer fazer cada vez melhor em seu trabalho. Você quer ajudar os 
outros ou ser um líder em seu ramo de atividade”. A frase ressalta que uma ligação afetiva com o trabalho em si deveria ser muito mais forte do que com seus frutos monetários.

A sugestão de expressar que colocaria os interesses próprios em segundo plano diante dos interesses da empresa pode ser ilustrada pelo conselho: "você colocaria os interesses da empresa na frente dos seus próprios? Outra pergunta capciosa. Se responder sim, você é alguém que não se preocupa com a família. Se responder não, não é alguém leal à empresa. Responda sim, porque você está, a essa altura, tentando ser o empregado perfeito, e empregados perfeitos não se importam em perder o jogo de futebol do filho para fazer hora extra". Outros conselhos nesse mesmo sentido sugerem que o entrevistado manifeste não ter restrições quanto a trabalhar fora do horário, em condições adversas e mesmo em outra cidade ou estado se isso for de interesse da empresa. Entretanto, não basta somente colocar os interesses da empresa acima dos pessoais. Espera-se essa mesma postura com relação aos valores, como pode ser apreendido pela frase: "responda sempre do ponto de vista das empresas. Elas querem contratar executivos que se adaptem à sua filosofia, e eliminarão quem discordar das suas políticas e práticas".

As frases escolhidas para ilustrar a questão da lealdade demandada chamam a atenção para uma questão ética: a amnésia com relação a problemas com chefes anteriores, a negação dissimulada da importância do dinheiro e de outros interesses pessoais diante dos interesses da empresa e a ocultação de pontos de vista pessoais se estes forem conflitantes com os da empresa são considerados legítimos pelos scripts analisados. Esses aspectos serão tratados no tópico destinado à discussão dos scripts éticos.

\section{O interesse prescrito}

Os sítios analisados estimulam os candidatos a expressar interesse pela entrevista, pela vaga e pela empresa, seja verbalizando explicitamente o interesse (conselho expresso em 26\% dos sítios que prescrevem o interesse), seja emitindo sinais que seriam encarados pelo entrevistador como sintomáticos do interesse ( $96 \%$ dos sítios que prescrevem o interesse). O sinal de interesse mais vislumbrado, presente em 100\% dos sítios que sugerem a emissão de tais sinais, é demonstrar conhecimentos prévios sobre a empresa, como ilustrado por esta frase extraída de um dos sítios da amostra: "faça a sua lição de casa: procure informações sobre a empresa que está convocando você para uma entrevista. Todo dirigente aprecia entrevistar um candidato que se mostra informado e que demonstrou interesse em saber sobre os negócios, as atividades, o mercado, a missão e a cultura da empresa".

Outros sinais de interesse que aparecem nos conteúdos analisados incluem aspectos relacionados à postura corporal e a recomendações explícitas de não olhar para o relógio durante a entrevista.

Enfim, o fato de ter comparecido à entrevista não parece ser um sinal suficientemente explícito de um interesse suficientemente intenso. O que se procura investigar não é a existência de interesse, mas sua intensidade. O que se busca é uma intensidade de interesse que torne possível prever a manutenção da lealdade desejável. Essa questão ressalta a interconexão magmática dos afetos prescritos, aqui tratados separadamente por questões analíticas.

\section{O respeito prescrito}

Os sítios analisados estimulam os candidatos a expressar respeito pelo entrevistador, pelo lugar da entrevista e pela empresa por meio de sinais sintomáticos.

São muitos os sinais de respeito identificados nos conteúdos analisados, sendo os mais frequentes o tratamento cortês ao entrevistador e a atitude de manter o telefone celular 
desligado durante o tempo da entrevista (ambos expressos em $41 \%$ dos sítios que prescrevem o respeito). Não fumar, não demonstrar intimidade excessiva e não fazer piadas durante $o$ encontro também aparecem com alguma recorrência nos sítios que prescrevem o respeito (respectivamente com 45\%, 35\% e 24\% de frequência). Há ainda, nessa categoria, alguns conselhos que poderiam parecer óbvios, como não "cantar" o entrevistador, apertar a mão do entrevistador quando ele estendê-la e não comparecer à entrevista alcoolizado.

Os sinais de respeito expressam uma nítida relação de poder entre entrevistador e entrevistado que prenunciam a aceitação tácita de uma relação de poder entre trabalhador e empresa. $\mathrm{O}$ entrevistador aparece como aquele que pode fumar, mas cujo cigarro, se for oferecido, deve ser gentilmente recusado pelo entrevistado; ao entrevistador é permitido atender seu telefone, mas o entrevistado deve evitar prestar atenção na conversa em sinal de respeito; rir comedidamente de uma piada proferida pelo entrevistador também aparece como uma obrigação do entrevistado, apesar de o entrevistado não poder tomar a iniciativa de contar uma piada; e, finalmente, ao entrevistador são permitidas ações desrespeitosas, mas isso deve ser encarado como uma forma de averiguar a capacidade do entrevistado em lidar com a pressão.

O conjunto dos afetos mais comumente prescritos - lealdade, interesse e respeito -, como não poderia deixar de ser, caracterizam investimentos sublimados de sinal positivo, isto é, prazeroso com relação à empresa. Além disso, são afetos típicos de uma relação desigual, heterônoma, uma vez que a lealdade, o interesse e o respeito são postulados nos scripts em uma direção única: do trabalhador para a empresa, incondicionalmente, mesmo que não haja reciprocidade.

\section{Scripts emocionais}

Dos sítios selecionados para a amostra, 90\% contêm scripts emocionais, na forma de recomendações sobre que emoções devem ser disfarçadas e quais devem ser expressas nas entrevistas de emprego. Das emoções a serem disfarçadas, a que aparece com maior frequência é a insegurança (conselho expresso em $78 \%$ dos sítios que prescrevem um script emocional). São escassas as sugestões de como realizar um trabalho emocional (deep acting) para que a insegurança não surja, mas são diversos os sinais relatados de insegurança que devem ser evitados (surface acting): ausência de contato visual com o entrevistador, expressão facial tensa, falar demais ou de menos, comparecer acompanhado de outra pessoa ao local da entrevista, roer as unhas, gaguejar e exagerar nos gestos são os exemplos mais frequentes. Trata-se de uma ampla lista imprecisa de estereótipos não comprovados e que desconsidera diferenças culturais, de personalidade e os desenvolvimentos etiológicos recentes sobre a gagueira. Sugestões mais gerais, como demonstrar autoconfiança, falar com naturalidade e manter-se calmo, aparecem, respectivamente, com a frequência de $44 \%, 40 \%$ e $24 \%$ nos sítios que prescrevem algum script emocional. Outra emoção que deve ser escondida, segundo as publicações analisadas e já abordada, é o ódio a antigos empregadores.

A emoção positiva por excelência que deve manifestada (citada por 59\% dos sítios que prescrevem um script emocional) é o entusiasmo. Obviamente não se está falando de um entusiasmo qualquer, mas de um entusiasmo com o trabalhar, como ilustrado por essa frase extraída de um dos sítios: "nada de postura apática. O que toda empresa procura é um profissional com garra e animado para executar novos projetos. Mostre que você tem foco no resultado, evitando dizer que deseja ser contratado para aprender mais dentro da companhia". 
Alguns textos chegam a afirmar, invocando provas científicas, que o entusiasmo e a segurança têm mais poder de persuadir o entrevistador do que o conhecimento: "além disso, uma postura pessoal de entusiasmo, autoconfiança e a maneira de se expressar segura e objetiva, poderão causar um impacto positivo no seu entrevistador. Está provado cientificamente: mais importante do que o conteúdo de nossas palavras é a forma com que nos expressamos".

\section{Scripts estéticos}

Dos sítios analisados, 70\% fazem prescrições de natureza estética ao entrevistado. A categoria mais frequentemente alvo de recomendações de natureza estética diz respeito à vestimenta ( $80 \%$ dos sítios que prescrevem script estético), seguida da fala (67\% dos sítios que prescrevem script estético). Outras categorias presentes na amostra pesquisada dizem respeito à postura corporal ao sentar-se, à presença de barba e cabelos longos, ao mascar chicletes, à presença de tatuagens e à obesidade.

\section{A vestimenta prescrita}

As vestes do entrevistado são frequentemente comparadas à embalagem do produto que se pretende vender, como pode ser visto nesta recomendação extraída de um dos sítios pesquisados: "a presença física é como a embalagem de um produto, precisa ser atraente e adequada ao cargo que pretende ocupar. Não estamos defendendo que você precise ser um modelo de beleza, mas simplesmente que procure passar uma impressão favorável desde o primeiro momento. Vestir-se com bom gosto e de forma adequada ao cargo que pretende ocupar, e observar os cuidados básicos sobre higiene pessoal, sem exageros com pintura e perfumes". Supõe-se que o bom gosto e a adequação da vestimenta sejam conceitos naturais compartilhados por todos, e não culturais.

A vestimenta prescrita é o único script na amostra no qual se pode verificar distinção de gênero: "para as mulheres, a dica é: evite barriga de fora e decotes, cores muito marcantes, perfume muito forte e acessórios em excesso. Na dúvida, aposte no tradicional". É exatamente nos scripts para a vestimenta feminina que é possível encontrar conselhos mais específicos, como os da frase selecionada. O tom geral é a recomendação de que a vestimenta deve ser adequada ao cargo e à cultura da empresa, além de ser neutra o suficiente para não revelar alguma identidade individual. Se a roupa se assemelha a uma embalagem, o que se busca é uma embalagem que não seja nem chamativa nem desleixada, mas clássica e sóbria, segundo padrões elitizados que não necessariamente são conhecidos por aqueles a quem o script se destina.

\section{A fala prescrita}

A fala prescrita pelos sítios analisados afirma uma superioridade social: a fala que sinaliza competência tem correção formal e não utiliza gírias ou palavrões: "evite falar gírias, expressões e jargões comuns. Exemplos: 'a nível de', 'né', 'aî', 'brother', 'irmão', 'meu', 'vamos supor que', etc.". Ao contrário da vestimenta prescrita, que deve ser adaptada à cultura da empresa, a fala é objeto de prescrições universalistas: a dimensão estética da linguagem verbal não é cultural, o que existe é fala correta e incorreta, superior e inferior. 


\section{Scripts éticos}

Os scripts éticos presentes nos conteúdos da amostra são confusos e contraditórios. Em 20\% dos sítios analisados foi constatada uma recomendação expressa ao entrevistado para não mentir, mas a razão citada para isso normalmente não tem nenhum conteúdo ético: resume-se ao risco de a mentira ser descoberta. Entretanto, como abordado anteriormente, recomenda-se frequentemente que o entrevistado minta com relação a suas experiências anteriores de emprego se elas não tiverem sido boas, à importância da remuneração e outros interesses pessoais diante dos interesses empresariais e dos pontos de vista que possam ser diferentes dos da empresa. Há ainda as recomendações explícitas para que o entrevistado dissimule sinais exteriores de emoções e que se apresente para a entrevista nos padrões estéticos da empresa, não importa se o entrevistado os compartilha. Enfim, o objetivo da conquista de uma posição no mercado de trabalho torna a verdade menos importante: a ética prescrita é a ética do cinismo racional.

\section{Vários scripts, um único conselho: adapte-se ou mofe na prateleira}

É instigante verificar que todos os conteúdos analisados restrinjam-se a conselhos de como obter uma avaliação positiva por parte do entrevistador, mas que nenhuma linha seja dedicada a dar conselhos de como o entrevistado pode avaliar a empresa que está recrutando para ajudá-lo a decidir se quer ou não trabalhar lá. Se há recomendações para que o entrevistado faça perguntas ao entrevistador, o motivo é simplesmente demonstrar interesse. Em contrapartida, perguntas que deem ao entrevistado a possibilidade de conhecer coisas relevantes da empresa, como sua política salarial e de benefícios, estão proibidas: não seria de bom tom. Em uma relação mediada pelas leis de mercado, pela oferta e demanda, o poder estará ao lado da escassez. Ao outro lado caberia adaptar-se. Essa tese é importante para a PO: não há como pensar a relação trabalhador-mercado a não ser como uma relação de poder.

Considerar a economia de mercado como socialmente instituída implica que a psique pode estabelecer com ela dois tipos de relação distintos: heterônoma (adaptativa) ou autônoma (que faça uso de sua capacidade de reflexividade crítica e da ação deliberada).

A análise dos scripts para as entrevistas de emprego evidencia que o tipo de relação prescrito é o adaptativo: aos afetos, às emoções, à estética e à ética demandada pelo mercado. $\mathrm{O}$ mercado demanda trabalhadores que, à semelhança do Ricardo de Shakespeare, sejam capazes de umedecer a face com lágrimas artificiais, tenham um rosto para cada ocasião, adicionem cores ao camaleão e troquem de forma como Proteu, segundo a conveniência da situação e a labilidade da demanda. A adaptação se institui como ideologia, a adaptabilidade como competência e a relação trabalhador-mercado como alienada, não reflexiva. Dessa forma, torna-se evidente que pressões ingênuas da ideologia da adaptação constituem o material de que são feitos esses scripts, tentativas de pré-formar subjetividades não reflexivas, poder exercido pela sociedade instituída.

Toda sociedade heterônoma tem a necessidade de atribuir a origem de suas normas a um ser transcendental. Nas sociedades históricas pré-capitalistas era a vontade de Deus ou dos ancestrais. Na sociedade contemporânea, as leis de mercado. Não é à toa que os scripts para o palco das entrevistas de emprego tentem dar aparência da mais completa espontaneidade à norma da oferta e procura. Nesse estado de coisas, os trabalhadores que se colocam no mercado de trabalho "são ao mesmo tempo os promotores das mercadorias e as mercadorias que promovem. São simultaneamente o produto e seus agentes de marketing, os bens e seus 
vendedores" (Bauman, 2008, p. 13). Da necessidade de subsumir o trabalhador de corpo e alma decorre que não apenas a força de trabalho, mas as próprias pessoas sejam transformadas em mercadoria que precisam se posicionar como marca, isto é, com uma identidade (ou subjetividade) atraente.

Na relação trabalhador-mercado que se institui, o mercado é o sujeito (cartesiano) que percebe, examina, avalia, compara e atribui sentido como o senhor da significação. $O$ trabalhador é reificado em objeto (não durável) de consumo. Não há quem discorde que o sentido do termo empregabilidade numa economia de mercado esteja relacionado à capacidade de obter atenção (do mercado) e atrair demanda e fregueses (empregadores). Reificações incompletas significam defeitos à empregabilidade. Defeitos (se não forem muito graves) podem ser corrigidos pela adaptação; caso contrário, opera-se uma dupla exclusão do sujeito: econômica (a não possibilidade de conseguir os meios de sustento) e simbólica (a pecha de incompetente), em que esta justifica aquela.

\section{Considerações finais}

No domínio do mercado de trabalho a exclusão se constitui em uma sanção particularmente severa e seu efeito se desdobra por todas as outras dimensões da existência humana (relações familiares, pessoais, amorosas), deixando marcas psíquicas, obstaculizando a construção da autoestima, do autorrespeito e da autoconfiança. Para além da questão do sustento, a conquista do emprego é plena de conteúdo simbólico, construído social e historicamente; portanto, as relações de trabalho não são redutíveis somente a disposições econômicas abstratas funcionando por meio de leis próprias e autônomas.

A PO deve reconhecer que a interação social torna os sujeitos vulneráveis, uma vez que a construção e a manutenção de uma relação positiva consigo mesmo só são possíveis com a ajuda da concordância e das reações afirmativas de outros sujeitos: "sem a referência a esses pressupostos intersubjetivos é completamente impossível explicar por que uma pessoa sofre danos quando um aspecto específico do entendimento de si próprio é destruído por certas ações, falas ou circunstâncias" (Honneth, 1997, p. 24). Certamente, a dimensão intersubjetiva está profundamente imersa na dimensão social-histórica. Esse estudo focalizou uma relação intersubjetiva que ocorre no domínio do mercado de trabalho tal como instituído. Esse domínio impõe regras sociais que se revelam nos scripts analisados. São regras específicas, dados da realidade instituída que se pretendem interiorizados por todos e que acabam por regular não só a relação com o Outro, mas a relação consigo mesmo. Moldam a consciência, os afetos e as vontades que um sujeito tem para com seu próprio self, no que diz respeito às capacidades e direitos que essa pessoa pode vivenciar. A exclusão social leva à exclusão, pelo indivíduo, de parte de seu próprio self, por meio da introjeção da falta de inclusão social e da repressão de parte de sua personalidade, o que gera, consequentemente, um sofrimento psíquico que aparece nas condições específicas nas quais o humano é chamado a se relacionar com um mercado de trabalho que se institui como o senhor racional da significação.

\section{Referências}

Bauman, Z. (2008). Vida para consumo: a transformação das pessoas em mercadoria. Rio de Janeiro: Zahar.

Castoriadis, C. (2007). Sujeito e verdade no mundo social-histórico. Rio de Janeiro: Civilização Brasileira. 
Castoriadis, C. (1999). Encruzilhadas do labirinto: feito e a ser feito (vol. 5). São Paulo: Paz e Terra.

Elias, N. (1994). O processo civilizador. Rio de Janeiro: Zahar. (originalmente publicado em 1939)

Goffman, E. (1993). A apresentação do eu na vida de todos os dias. Lisboa: Relógio D'água. (originalmente publicado em 1959)

Gorz, A. (2005). O imaterial: conhecimento, valor e capital. São Paulo: Annablume.

Honneth, A. (1997). Recognition and moral obligation. Social Research, 60 (1), 16-35.

Limongi-França, A. C. \& Arellano, E. B. (2002). Os processos de recrutamento e seleção. In M. T. L. Fleury (Org.), As pessoas na organização. São Paulo: Gente.

Malvezzi, S. (1999). Psicologia Organizacional. Da administração científica à globalização: uma história de desafios. In C. G. Machado (Org.), Actas do Congresso Internacional "Interfaces da Psicologia" (pp 313-32, vol. 2). Évora: Universidade de Évora.

Reich, B. R. (1994). O trabalho das nações. São Paulo: Educator.

Salvatore, S. \& Vernuleo C. (2008). Understanding the role of emotion in sense-making: a semiotic psychoanalytic oriented perspective. Integrative Psychological $\mathcal{E}$ Behavioral Science, 42 (1), 32-43.

Wright-Mills, C. (1979). A nova classe média (3ª ed.). Rio de Janeiro: Zahar. (originalmente publicado em 1951)

\section{Endereço para correspondência}

cesarmg@usp.br

Recebido em: 16/10/2010

Revisado em: 22/03/2011

Aprovado em: 22/04/2011 